\title{
Sites of extranodal involvement are prognostic in patients with stage 1 follicular lymphoma
}

\author{
Aditi Shastri ${ }^{1}$, Murali Janakiram ${ }^{1}$, Ioannis Mantzaris' ${ }^{1}$, Yiting Yu ${ }^{2}$, Jaime S. Londono ${ }^{1}$, \\ Amit K. Verma ${ }^{1}$ and Stefan K. Barta ${ }^{3}$ \\ ${ }^{1}$ Division of Hematologic Malignancies, Department of Oncology, Montefiore Medical Center \& Albert Einstein College of \\ Medicine, Bronx, NY, USA \\ ${ }^{2}$ Department of Biostatistics, Albert Einstein College of Medicine, Bronx, NY, USA \\ ${ }^{3}$ Department of Medical Oncology, Fox Chase Cancer Center, Philadelphia, PA, USA \\ Correspondence to: Aditi Shastri, email: ashastri@montefiore.org
}

Keywords: follicular lymphoma, Surveillance, Epidemiology and End Results database, prognosis, extranodal disease

Received: March 29, $2017 \quad$ Accepted: June 19, $2017 \quad$ Published: July 14, 2017

Copyright: Shastri et al. This is an open-access article distributed under the terms of the Creative Commons Attribution License 3.0 (CC BY 3.0), which permits unrestricted use, distribution, and reproduction in any medium, provided the original author and source are credited.

\section{ABSTRACT}

Objectives: Follicular lymphoma (FL) is the most common indolent B cell lymphoma in the United States and a quarter of patients present with stage I disease. The objective of this study was to examine if primary site of disease influences survival in early stage lymphoma.

Results: The most common extranodal primary sites were the integumentary system ( $8 \%)$, followed by the GI tract $(6.4 \%)$ and head \& neck $(5.6 \%)$. We stratified patients into a pre-rituximab era (1983-1998) and the rituximab era (1999-2011). In multivariable analysis, integumentary disease was associated with better overall survival (Hazard Ratio [HR], 0.77; Confidence Interval [CI], 0.66-0.9) while primary site FL of the nervous system (HR, 2.40; CI, 1.72-3.38) and the musculoskeletal system (HR, 2.14; CI, 1.44-3.18) were associated with worse overall survival when compared to primary nodal FL. Treatment in the pre-rituximab era, male gender and older age at diagnosis were associated with worse survival.

Methods: We queried the SEER database from 1983 to 2011. We included all adult patients (>18 years) with histologically confirmed stage I $\mathbf{F L}$, active follow-up, and a single primary tumor. A total of 9,865 patients met eligibility criteria, with 2520 $(25 \%)$ having an extranodal primary site. We classified the primary sites by organ or anatomic location into 11 sites.

Conclusion: Primary site of disease is a prognostic factor for patients with early stage FL and may help identify subsets of patients that could benefit from early, aggressive treatment.

\section{INTRODUCTION}

Follicular lymphoma (FL) is the most common subtype of indolent lymphomas and accounts for $35 \%$ of all Non-Hodgkin's Lymphomas in the United States [1-3]. In approximately $85 \%$ of FL patients, the lymphoma cells harbor the pathognomonic translocation $\mathrm{t}(14 ; 18)(\mathrm{q} 32$; q21) leading to overexpression of the BCL2 oncogene, an essential step in the pathogenesis of FL [4]. FL is a heterogeneous disease with variable biologic behavior and clinical course. The Follicular Lymphoma International Prognostic Index or FLIPI score is the most commonly used prognostic tool that has been revised and validated in the rituximab era (FLIPI-2)[5, 6]. Notwithstanding the prognostic classification, treatment of follicular lymphoma is guided primarily by the extent of disease involvement [7]. Advanced stage FL (stage III/IV) is considered an incurable but indolent disease for which the decision to treat is based on several well-established clinical criteria. In contrast, treatment of limited stage FL (stage I and 
contiguous stage II) has the potential to result in long-term disease-free survival, however the treatment modality of choice is not well defined $[7,8]$.

Several consensus based practice guidelines recommend radiation therapy (RT) as the preferred treatment for stage 1 follicular lymphoma, which represents approximately $25 \%$ of the presenting cases of FL $[9,10]$. However, the optimal radiation dose and field size have not been definitively determined to date [10-12] An analysis of the National Lymphocare Study, a large prospective cohort study of patients with FL, revealed that only $27 \%$ of the patients with early stage disease were treated with RT while others were only observed, received single-agent rituximab, or a combination of rituximab with chemotherapy with or without subsequent radiotherapy [10]. These practices likely reflect uncertainty over the most beneficial initial treatment strategy coupled with concern about the short and long-term treatment related toxicities of RT and/or chemoimmunotherapy. Evidence suggests that the site of involvement is associated with outcome in several Non-Hodgkin's lymphomas (NHL's) [13-17]. Therefore identifying subsets of patients with pathobiologically different tumor types could help tailor initial therapy employed in managing limited stage follicular lymphoma. The objective of this study was to assess how the primary site of involvement influences prognosis and can inform therapy in stage I follicular lymphoma.

\section{RESULTS}

\section{Patient characteristics}

We identified 14,059 adult cases of histologically confirmed Stage I follicular lymphoma from 1983-2011, of whom 9,865 patients met eligibility criteria (Figure 1). Extranodal primary site was noted in 2,520 patients (25.5\%). Patient characteristics are outlined in Table 1. Briefly, of the patients analyzed, 4,749 (48\%) were male, $8,833(90 \%)$ were white and 5,459 (55\%) were older than age 60 . The median age in our series was similar between patients presenting with primary LN disease versus extranodal disease (61.5 vs. 61.8 years). The most common extranodal primary sites were the integumentary system $(31.5 \%)$, followed by GI tract $(25 \%)$, Head \& Neck (21.9\%) and Breast (4.8\%; Figure 2).

\section{Survival analysis}

We performed a survival analysis comparing each primary extranodal site of disease with LN primary disease. On univariable analysis, integumentary disease was associated with better overall survival $(\mathrm{p}=0.001$, HR $0.74,95 \%$ CI $0.63-0.86$ ) when compared to a nodal primary site. Primary disease of the respiratory system was associated with worse OS ( $p=0.037$, HR: $1.68,95 \%$
CI 1.18-2.4) as well as primary disease of the muscle \& connective tissue system ( $\mathrm{p}=0.003$, HR: 2.02, CI: 1.373; Table 2). On multivariable analysis, integumentary disease remained associated with better OS ( $p=0.001$, HR 0.77 , CI 0.66 to 0.9 ), while primary disease of the nervous system ( $p=0.01$, HR 2.4 , CI 1.72 to 3.38 ) and muscle \& connective tissue system ( $p=0.001$, HR 2.14 , CI 1.44 to 3.18 ) were associated with worse OS. Primary respiratory site was no longer significantly associated with survival on multivariate analysis ( $\mathrm{p}=0.66$, HR 1.39 , CI 0.977 to 1.986; see also Table 2 and Figure 3 ). The other primary sites were not significantly associated with differential OS compared to LN primary site.

Patients treated in the pre-rituximab era had a worse OS on multivariate analysis than if treated in the rituximab era ( $<<0.001$, HR: 1.59 , CI: 1.43-1.73). Female sex was associated with better OS ( $p<0.001$, HR: 0.76, CI: 0.710.81 ); increased age at diagnosis was associated with decreased survival and for every one-year increment in age, the risk of death increased by $7.1 \%(\mathrm{p}<0.001$, HR: 1.071, CI: 1.07-1.08). Patients who underwent treatment for their stage I FL with either surgery ( $<<0.001, \mathrm{HR}: 1.58$, CI: 1.46-1.71) or radiation ( $\mathrm{p}<0.001$, HR 1.36 , CI 1.261.47) had better survival than those who did not receive these therapies. Race was not associated with OS.

\section{DISCUSSION}

In a large, nationally representative, retrospective cohort study of patients with stage $1 \mathrm{FL}$, we observed that specific sites of involvement are associated with better or worse survival after adjusting for age, sex, race and therapy. Although patients with FL have an excellent median OS approaching 20 years in the modern chemotherapy era, a majority of patients continue to relapse within 5 years of their initial treatment. The treatments they receive are also associated with second malignancies and organ dysfunction [18-20].

Finding additional prognostic factors that supplement the FLIPI score will help refine it and risk stratify patients as having good versus poor risk. This in turn will guide therapeutic decision-making that will improve the quality of life for good risk patients and decrease the impact of overtreatment and the accompanying financial toxicity of cancer treatment.

Our findings demonstrate that stage $1 \mathrm{FL}$ of the integumentary system has a significantly better outcome than LN primary disease. Primary cutaneous follicular lymphoma (PCFL) has traditionally been associated with an improved survival and response to therapy in prior studies $[21,22]$. It is also designated as a specific category in the WHO classification [23]. These findings suggest that Stage I FL of the integumentary system is pathobiologically a different disease than LN primary disease. This may be due to the previously described rare expression of BCL-2 and a different gene signature 
in comparison to nodal follicular lymphoma [24-27]. In comparison, stage I FL of the muscle $\&$ connective tissue system and nervous system have a significantly worse survival than LN primary disease while other disease sites like the GI tract, head \& neck, and respiratory system are not significantly associated with worse survival on multivariate analysis. Muscle \& connective tissue disease being anatomically closer to bone, may represent transformed FL and this could explain the poor outcomes. A case series in the literature suggest that nervous system involvement by NHL carries a very poor prognosis with overall survival approximated at 4 months [28]. Although most cases of primary CNS lymphoma reported in the literature are diffuse large B cell lymphomas, a minority of cases has been pathologically confirmed to be follicular lymphoma. These cases retained the poor prognosis similarly to what we observed in our study [29]. The integumentary system and GI tract were the most commonly involved extranodal site of disease as previously reported [30]. Otherwise only limited data on the prognostic significance of non-cutaneous extranodal sites of FL exists which limits deriving definite conclusions on their impact on survival $[31,32]$.

Multiple epidemiological studies conducted have indicated that NHL characteristics, incidence and survival rates are influenced by race. This is less clear for FL probably due to the long indolent course of the disease and good overall survival [18, 33-37]. In our study we found no association of race on overall survival for stage I FL. $\mathrm{FL}$ is much more common in Whites than in other races

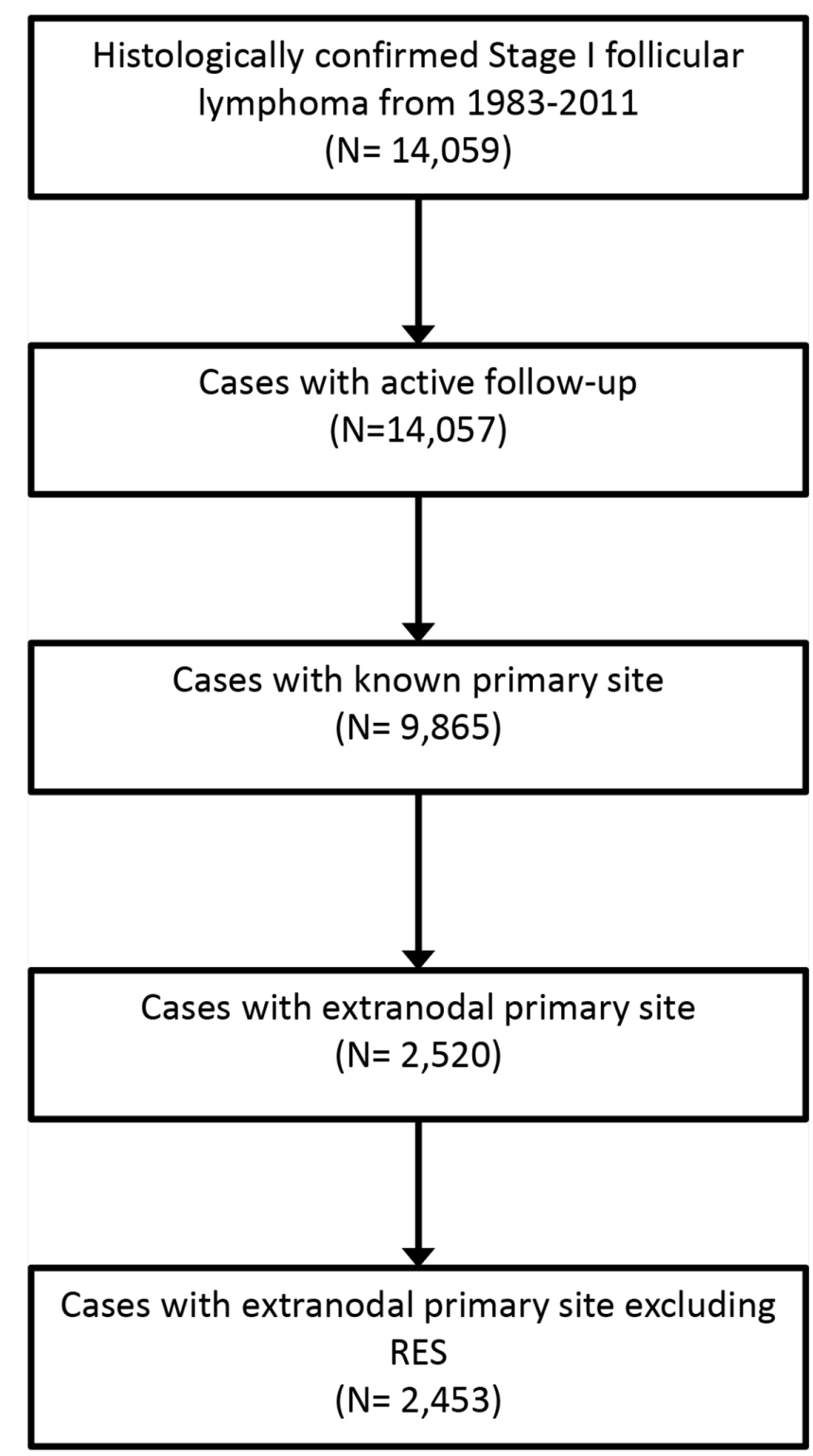

Figure 1: Flowchart showing selection of patients.

RES, reticuloendothelial system. 
Table 1: Baseline characteristics and comparison within and across primary site categories ${ }^{1}$

\begin{tabular}{|c|c|c|c|c|c|c|}
\hline Primary site & Total no. & $\begin{array}{c}\text { Age }>60 \\
\text { (years) }\end{array}$ & Males & White & Black & $\begin{array}{c}\text { Other }+ \\
\text { unknown* }\end{array}$ \\
\hline Lymph Node & $7,411(75)$ & $4,031(54)$ & $3,572(48)$ & $6,718(91)$ & $303(4)$ & $390(5)$ \\
\hline $\begin{array}{l}\text { Integumentary } \\
\text { system }\end{array}$ & $793(8)$ & $412(52)$ & $438(55)$ & 703 (89) & $43(5)$ & $46(6)$ \\
\hline GI tract & $632(6)$ & $383(61)$ & $310(49)$ & $564(89)$ & $18(3)$ & $49(8)$ \\
\hline Head \& Neck & $552(5)$ & $341(62)$ & $264(48)$ & $480(87)$ & $28(5)$ & $44(7)$ \\
\hline Breast & $123(1)$ & $91(74)$ & $5(4)$ & $109(89)$ & $7(6)$ & $7(6)$ \\
\hline $\begin{array}{l}\text { Nervous } \\
\text { system }\end{array}$ & $77(0.7)$ & $41(53)$ & $41(53)$ & $67(87)$ & $4(5)$ & $6(7)$ \\
\hline $\begin{array}{l}\text { Genitourinary } \\
\text { system }\end{array}$ & $69(0.7)$ & $37(54)$ & $31(45)$ & $58(84)$ & $9(13)$ & $2(3)$ \\
\hline $\begin{array}{l}\text { Endocrine } \\
\text { system }\end{array}$ & $63(0.6)$ & $31(49)$ & $12(19)$ & $59(94)$ & $0(0)$ & $3(5)$ \\
\hline Muscle \& CT & $62(0.6)$ & $36(58)$ & $37(60)$ & $59(95)$ & $2(3)$ & $1(2)$ \\
\hline $\begin{array}{l}\text { Respiratory } \\
\text { system }\end{array}$ & $62(0.6)$ & $43(69)$ & $28(45)$ & $57(92)$ & $2(3)$ & $3(5)$ \\
\hline $\begin{array}{l}\text { Thymus, } \\
\text { mediastinum } \\
\& \text { heart }\end{array}$ & $20(0.2)$ & $13(65)$ & $11(55)$ & $18(90)$ & $1(5)$ & $1(5)$ \\
\hline Total & 9,865 & $5,459(55)$ & $4,749(48)$ & $8,833(90)$ & $417(4)$ & $552(6)$ \\
\hline
\end{tabular}

CT, cardiothoracic; GI, gastrointestinal.

${ }^{1}$ Data are presented as number $(\%)$ unless otherwise indicated.

*Other represents race recodes for American Indian, AK Native, Asian \& Pacific Islander; Unknown represents race recode for unknown race.

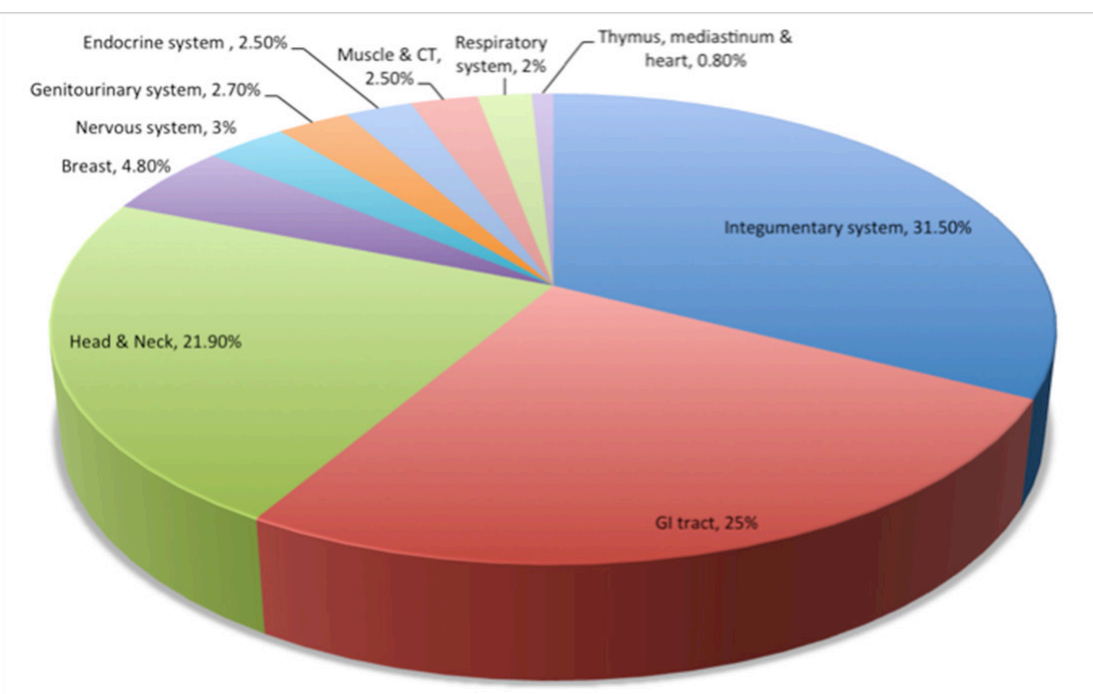

Figure 2: Primary extranodal sites of involvement.

CT, cardiothoracic; GI: gastrointestinal.

*Cases not included here are those that have a known but unclassified primary site and reticuloendothelial system as a primary site. 
Table 2: Cox proportional hazards model showing overall survival, stratified by primary site

\begin{tabular}{lccccc}
\hline \multirow{2}{*}{ Primary site } & \multicolumn{2}{c}{ Univariable analysis } & & \multicolumn{2}{c}{ Multivariable analysis } \\
\cline { 2 - 3 } \cline { 5 - 6 } & HR (95\% CI) & P value & & HR (95\% CI) & P value \\
\hline Integumentary System & $0.74(0.63-0.86)$ & 0.001 & & $0.77(0.66-0.90)$ & 0.001 \\
Respiratory System & $1.68(1.18-2.4)$ & 0.037 & & $1.39(0.97-1.99)$ & 0.66 \\
Musculoskeletal & $2.02(1.37-3.0)$ & 0.003 & & $2.14(1.44-3.18)$ & 0.001 \\
System & $1.92(1.37-2.69)$ & 0.001 & & $2.40(1.72-3.38)$ & 0.011 \\
Nervous System & & & & &
\end{tabular}

$\mathrm{CI}$, confidence interval; HR, hazard ratio; RES, reticuloendothelial system, p-value adjusted by Bonferroni correction.

[38]. We similarly found a much smaller representation of Black and other races $(10 \%)$ in comparison to Whites (90\%), which may further limit statistical power to detect a small survival differences based on race. Older age and male sex predicted for inferior patient survival in our study as previously reported $[6,10]$.

The use of radiation therapy in early stage FL has been associated with improved OS after correcting for socio-demographic, tumor and treatment factors $[10,39]$. Involved-field RT is a commonly used treatment modality for early-stage FL [40]. Rituximab has also emerged as an efficient systemic therapy, though clinical data are limited regarding its impact in early stage FL. Although radiation therapy is considered to be better tolerated than chemoimmunotherapy, its use in early stage FL continues to decline in favor of alternative treatment strategies of single agent chemotherapy or observation [39]. We found a beneficial effect on OS when patients were initially treated with radiation therapy for their stage I FL. Our observation is in contrast to the general paradigm that the watch $\&$ wait approach is equivalent to the early treatment approach and supports findings from a growing body of literature that has shown improvement in quality of life indices as well as improvement in OS with the early treatment approach, making a case for carefully selecting the patient population that can benefit from this strategy $[39,41,42]$.

The SEER database represents $28 \%$ of the United States population and provides a real world, multi-ethnic setting to further study the association between specific sites of involvement by follicular lymphoma, its clinical characteristics and outcomes. Our study is the largest to date to address this question for stage 1 follicular lymphoma.

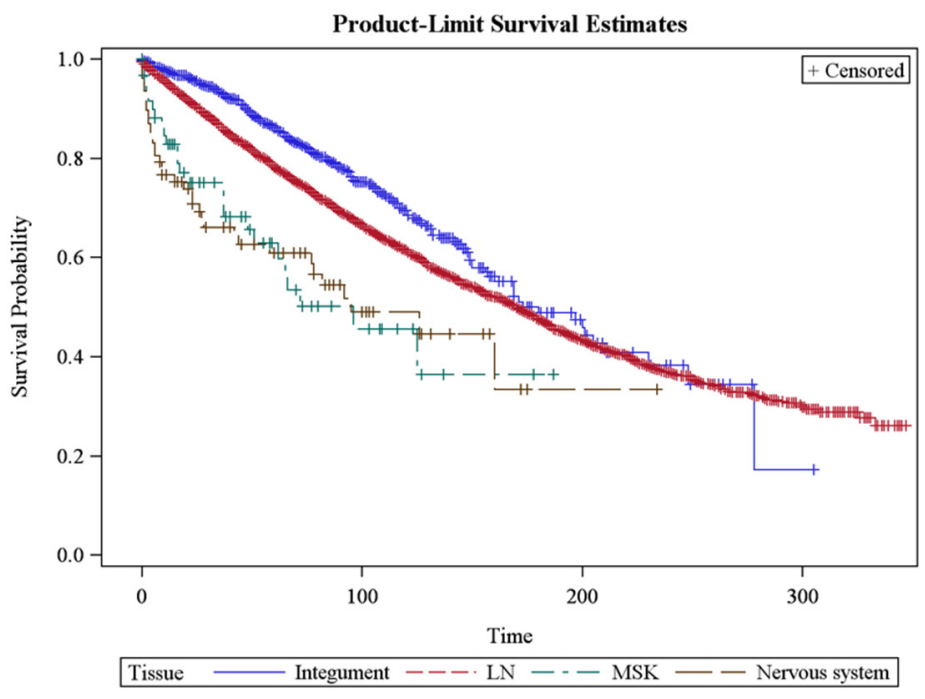

Figure 3: Kaplan-Meier curve demonstrating overall survival of patients with stage I follicular lymphoma. (A) Lymph node primary site vs. integumentary system (median OS 170 vs. 180 months, p =0.001, blue line); (B) lymph node primary site vs. musculoskeletal system (median OS 170 months vs. 96 months, $\mathrm{p}=0.001$, green hatched line); and (C) lymph node primary site vs. nervous system (median OS 170 vs. 95 months, $\mathrm{p}=0.01$, brown hatched line). OS for other sites not statistically significant compared to lymph node primary site. 
However, a limitation of the SEER database is the lack of information about chemotherapy in the SEER database as a major modality of treatment for FL is chemoimmunotherapy. We partially addressed this issue by analyzing survival in pre-rituximab and rituximab era and in keeping with previously reported literature; we found an improved survival in the rituximab era [43]. Information about staging modalities is also limited. Staging patients accurately is the cornerstone of distinguishing early stage disease from disseminated disease. FDG-PET upstages a significant proportion of patients compared to conventional CT scans and aids in patients receiving the appropriate stage specific therapy and might not have been available for the majority of patients included in this analysis [10]. It is also unclear how many patients underwent a bone marrow biopsy as part of their staging work up. Incorporating information about staging modalities used in future studies will prove useful as the Lymphocare study reported that adequately staged patients had a better outcome regardless of the modality of treatment selected [10]. Another drawback is the lack of central pathologic confirmation [44]. Studies including patients diagnosed before 2001 had codes from earlier ICD-O versions that were converted to ICD-O-3 and have higher proportions of unclassified (e.g., lymphoma and not otherwise specified) cases. However, Clarke et al showed an $89 \%$ and $84 \%$ agreement between computer-converted ICD-O-2 codes to ICDO-3 codes and registry-assigned codes for follicular lymphoma cases diagnosed in the 1988-1994 and 1998- 2000 SEER periods respectively [45].

\section{MATERIALS AND METHODS}

\section{Patients}

We obtained data from the Surveillance, Epidemiology \& End Results (SEER) program. SEER collects cancer incidence, treatment, and survival information from 18 geographic areas in the United States, representing $28 \%$ of the entire US population [46, 47]. We used direct case listings extracted by SEER*Stat software version 8.1.5, released March 31,2014. This report includes all FL patients in the SEER database during $1 / 1 / 83$ and $12 / 31 / 11$.

\section{Measurements}

We identified patients with a diagnosis of FL using the International Classification of Disease for Oncology, $3^{\text {rd }}$ edition, ICD-0-3 histology code 9690, 9691, 9695, 9698 until the latest follow-up recorded in the SEER submission. These codes have been validated in previous studies [44, 48]. SEER identifies cases as follicular lymphoma based on several parameters that include histopathology, FISH testing, genetic testing for the BCL2 gene rearrangement, translocation $\mathrm{t}(14,18)(\mathrm{q} 32 ; \mathrm{q} 21)$ and immunophenotyping. Our inclusion criteria were Stage I FL patients, age $>18$ years, patients with active followup, and those with a single primary tumor. We excluded patients with a diagnosis established by autopsy and/or death certificate only, patients for whom the diagnosis of FL was a second or subsequent primary, and patients with an unknown primary site.

Primary sites were classified by organ or anatomic site into 1) head and neck 2) gastrointestinal (GI tract) 3) pulmonary system 4) thymus, mediastinum, and heart 5) muscle \& connective tissue 6) integumentary system 7) nervous system 8) breast tissue 9) genitourinary system 10) endocrine system and 11) lymphatic system. PCFL and stage I FL of the integumentary system represent the same entity, however prior to 2008, PCFL was not recognized and as such not reported as a separate entity [49, 50]. Hence, for ease of understanding, we refer to this category as the integumentary system throughout the paper. We excluded the category of blood and reticuloendothelial system as this includes disease in the bone marrow, which cannot be easily distinguished from more advanced stages of disease. We subsequently defined a pre-rituximab era (1983-1998) and the rituximab era (1999-2011) based on the year of FDA approval of rituximab for the treatment of FL in the US to indirectly estimate the effect of rituximab on survival.

\section{Statistical analysis}

We calculated OS as time in months from date of diagnosis and date of death, date last known to be alive, or the date of study cutoff. We performed descriptive statistics with Pearson's Chi-square test to analyze categorical variables. For continuous variables we used Mann Whitney or Student t tests, depending on the normality of distribution of data. OS estimates were calculated using Kaplan-Meier survival analysis. Multivariable Cox proportional-hazard regression models were fitted to evaluate the prognostic impact of each extranodal site of involvement using the lymph node group as reference, after adjustment for known prognostic factors such as age, sex, race, surgery, and radiation. All tests were two-tailed, with the threshold for significance of $p$ value set at 0.05 . The $p$-values were adjusted by the Bonferroni correction. All statistical analyses were performed using SAS, version 9.3.

\section{CONCLUSION}

In summary, primary site of disease is an important prognostic factor for patients with early stage FL as demonstrated by our population-based study. Patients with Stage I FL of the integumentary system had a significantly better outcome than primary nodal disease. Musculoskeletal and nervous system primary sites had 
a significantly worse survival than primary nodal sites. Furthermore, RT and surgery were associated with better survival than other treatment modalities, including expectant observation. This supports the hypothesis that a subset of patients with stage I FL may benefit from early and/or aggressive treatment in comparison to an observation only approach. It would be important to prospectively validate this finding in the current era of more accurate initial staging and more effective therapy that includes monoclonal CD20-directed antibodies.

In addition to its prognostic significance, primary site may correlate with certain biological characteristics associated with disease behavior and pathogenesis. Going forward it will be important to elucidate different pathobiological characteristics that may be specific to site of involvement by comprehensive genomic and mutational analysis. This might help identify pathways that can be therapeutically targeted with novel agents with low toxicity.

\section{CONFLICTS OF INTEREST}

The authors have declared no conflicts of interest.

\section{REFERENCES}

1. A clinical evaluation of the International Lymphoma Study Group classification of non-Hodgkin's lymphoma. The Non-Hodgkin's Lymphoma Classification Project. Blood. 1997;89:3909-3918.

2. Armitage JO, Weisenburger DD. New approach to classifying non-Hodgkin's lymphomas: clinical features of the major histologic subtypes. Non-Hodgkin's Lymphoma Classification Project. J Clin Oncol. 1998;16:2780-2795.

3. Morton LM, Wang SS, Devesa SS, Hartge P, Weisenburger DD, Linet MS. Lymphoma incidence patterns by WHO subtype in the United States, 1992-2001. Blood. 2006;107:265-276.

4. Freedman A. Follicular lymphoma: 2014 update on diagnosis and management. Am J Hematol. 2014;89:429-436.

5. Nooka AK, Nabhan C, Zhou X, Taylor MD, Byrtek M, Miller TP, Friedberg JW, Zelenetz AD, Link BK, Cerhan JR, Dillon H, Sinha R, Shenoy PJ, et al. Examination of the follicular lymphoma international prognostic index (FLIPI) in the National LymphoCare study (NLCS): a prospective US patient cohort treated predominantly in community practices. Ann Oncol. 2013;24:441-448.

6. Solal-Celigny P, Roy P, Colombat P, White J, Armitage JO, Arranz-Saez R, Au WY, Bellei M, Brice P, Caballero D, Coiffier B, Conde-Garcia E, Doyen C, et al. Follicular lymphoma international prognostic index. Blood. 2004;104:1258-1265.

7. Cheson BD, Fisher RI, Barrington SF, Cavalli F, Schwartz LH, Zucca E, Lister TA; Alliance, Australasian Leukaemia and Lymphoma Group; Eastern Cooperative Oncology Group; European Mantle Cell Lymphoma Consortium; Italian Lymphoma Foundation; European Organisation for Research; Treatment of Cancer/Dutch Hemato-Oncology Group, et al. Recommendations for initial evaluation, staging, and response assessment of Hodgkin and nonHodgkin lymphoma: the Lugano classification. J Clin Oncol. 2014;32:3059-3068.

8. Hiddemann W, Cheson BD. How we manage follicular lymphoma. Leukemia. 2014;28:1388-1395.

9. Zelenetz AD, Abramson JS, Advani RH, Andreadis CB, Bartlett N, Bellam N, Byrd JC, Czuczman MS, Fayad LE, Glenn MJ, Gockerman JP, Gordon LI, Harris NL, et al. Non-Hodgkin's lymphomas. J Natl Compr Canc Netw. 2011;9:484-560.

10. Friedberg JW, Byrtek M, Link BK, Flowers C, Taylor M, Hainsworth J, Cerhan JR, Zelenetz AD, Hirata J, Miller TP. Effectiveness of first-line management strategies for stage I follicular lymphoma: analysis of the National LymphoCare Study. J Clin Oncol. 2012;30:3368-3375.

11. Knoops L, Haas R, de Kemp S, Majoor D, Broeks A, Eldering E, de Boer JP, Verheij M, van Ostrom C, de Vries A, van't Veer L, de Jong D. In vivo p53 response and immune reaction underlie highly effective lowdose radiotherapy in follicular lymphoma. Blood. 2007;110:1116-1122.

12. Haas RL, Poortmans P, de Jong D, Aleman BM, Dewit LG, Verheij M, Hart AA, van Oers MH, van der Hulst M, Baars JW, Bartelink H. High response rates and lasting remissions after low-dose involved field radiotherapy in indolent lymphomas. J Clin Oncol. 2003;21:2474-2480.

13. Cheah CY, Campbell BA, Seymour JF. Primary breast lymphoma. Cancer Treat Rev. 2014;40:900-908.

14. Martinelli G, Ryan G, Seymour JF, Nassi L, Steffanoni S, Alietti A, Calabrese L, Pruneri G, Santoro L, KuperHommel M, Tsang R, Zinzani PL, Taghian A, et al. Primary follicular and marginal-zone lymphoma of the breast: clinical features, prognostic factors and outcome: a study by the International Extranodal Lymphoma Study Group. Ann Oncol. 2009;20:1993-1999.

15. Zinzani PL, Quaglino P, Pimpinelli N, Berti E, Baliva G, Rupoli S, Martelli M, Alaibac M, Borroni G, Chimenti S, Alterini R, Alinari L, Fierro MT, et al. Prognostic factors in primary cutaneous B-cell lymphoma: the Italian Study Group for Cutaneous Lymphomas. J Clin Oncol. 2006;24:1376-1382.

16. Castillo JJ, Winer ES, Olszewski AJ. Sites of extranodal involvement are prognostic in patients with diffuse large B-cell lymphoma in the rituximab era: an analysis of the Surveillance, Epidemiology and End Results database. Am J Hematol. 2014;89:310-314.

17. Ambinder AJ, Shenoy PJ, Nastoupil LJ, Flowers CR. Using primary site as a predictor of survival in mantle cell lymphoma. Cancer. 2013;119:1570-1577. 
18. Casulo C. Prognostic factors in follicular lymphoma: new tools to personalize risk. Hematology Am Soc Hematol Educ Program. 2016;2016:269-276.

19. Fowler N. Frontline strategy for follicular lymphoma: are we ready to abandon chemotherapy? Hematology Am Soc Hematol Educ Program. 2016;2016:277-283.

20. Tan D, Horning SJ, Hoppe RT, Levy R, Rosenberg SA, Sigal BM, Warnke RA, Natkunam Y, Han SS, Yuen A, Plevritis SK, Advani RH. Improvements in observed and relative survival in follicular grade 1-2 lymphoma during 4 decades: the Stanford University experience. Blood. 2013;122:981-987.

21. Hamilton SN, Wai ES, Tan K, Alexander C, Gascoyne $\mathrm{RD}$, Connors JM. Treatment and outcomes in patients with primary cutaneous B-cell lymphoma: the BC Cancer Agency experience. Int J Radiat Oncol Biol Phys. 2013;87:719-725.

22. Wilcox RA. Cutaneous B-cell lymphomas: 2015 update on diagnosis, risk-stratification, and management. Am J Hematol. 2015;90:73-76.

23. Campo E, Swerdlow SH, Harris NL, Pileri S, Stein H, Jaffe ES. The 2008 WHO classification of lymphoid neoplasms and beyond: evolving concepts and practical applications. Blood. 2011;117:5019-5032.

24. Pham-Ledard A, Cowppli-Bony A, Doussau A, Prochazkova-Carlotti M, Laharanne E, Jouary T, BelaudRotureau MA, Vergier B, Merlio JP, Beylot-Barry M. Diagnostic and prognostic value of BCL2 rearrangement in 53 patients with follicular lymphoma presenting as primary skin lesions. Am J Clin Pathol. 2015;143:362-373.

25. Carreras J, Lopez-Guillermo A, Roncador G, Villamor N, Colomo L, Martinez A, Hamoudi R, Howat WJ, Montserrat E, Campo E. High numbers of tumor-infiltrating programmed cell death 1-positive regulatory lymphocytes are associated with improved overall survival in follicular lymphoma. J Clin Oncol. 2009;27:1470-1476.

26. Koch K, Hoster E, Unterhalt M, Ott G, Rosenwald A, Hansmann ML, Engelhard M, Hiddemann W, Klapper W. The composition of the microenvironment in follicular lymphoma is associated with the stage of the disease. Hum Pathol. 2012;43:2274-2281.

27. Wahlin BE, Aggarwal M, Montes-Moreno S, Gonzalez LF, Roncador G, Sanchez-Verde L, Christensson B, Sander B, Kimby E. A unifying microenvironment model in follicular lymphoma: outcome is predicted by programmed death1--positive, regulatory, cytotoxic, and helper T cells and macrophages. Clin Cancer Res. 2010;16:637-650.

28. Spectre G, Gural A, Amir G, Lossos A, Siegal T, Paltiel O. Central nervous system involvement in indolent lymphomas. Ann Oncol. 2005;16:450-454.

29. Hollender A, Kvaloy S, Lote K, Nome O, Holte H. Prognostic factors in 140 adult patients with non-Hodgkin's lymphoma with systemic central nervous system (CNS) involvement. A single centre analysis. Eur J Cancer. 2000;36:1762-1768.
30. Fernandez de Larrea C, Martinez-Pozo A, Mercadal S, García A, Gutierrez-García G, Valera A, Ghita G, Colomo L, Gainza E, Villamor N, Nomdedeu B, Estrach T, Montserrat $\mathrm{E}$, et al. Initial features and outcome of cutaneous and noncutaneous primary extranodal follicular lymphoma. Br J Haematol. 2011;153:334-340.

31. Karadurmus N, Ataergin S, Erdem G, Cakar M, Emer O, Ozaydin S, Ozturk M, Safali M, Arpaci F. A rare presentation of follicular lymphoma: cerebellar involvement, successfully treated with a combination of radiotherapy and chemotherapy. Cancer Res Treat. 2013;45:234-238.

32. Padhi S, Paul TR, Challa S, Prayaga AK, Rajappa S, Raghunadharao D, Sarangi R. Primary extra nodal non Hodgkin lymphoma: a 5 year retrospective analysis. Asian Pac J Cancer Prev. 2012;13:4889-4895.

33. Marcos-Gragera R, Allemani C, Tereanu C, De Angelis R, Capocaccia R, Maynadie M, Luminari S, Ferretti S, Johannesen TB, Sankila R, Karjalainen-Lindsberg ML, Simonetti A, Martos MC, et al. Survival of European patients diagnosed with lymphoid neoplasms in 20002002: results of the HAEMACARE project. Haematologica. 2011;96:720-728.

34. Sader-Ghorra C, Rassy M, Naderi S, Kourie HR, Kattan J. Type distribution of lymphomas in Lebanon: five-year single institution experience. Asian Pac J Cancer Prev. 2014; $15: 5825-5828$.

35. Smith A, Howell D, Patmore R, Jack A, Roman E. Incidence of haematological malignancy by sub-type: a report from the Haematological Malignancy Research Network. Br J Cancer. 2011;105:1684-1692.

36. Yoon SO, Suh C, Lee DH, Chi HS, Park CJ, Jang SS, Shin HR, Park BH, Huh J. Distribution of lymphoid neoplasms in the Republic of Korea: analysis of 5318 cases according to the World Health Organization classification. Am J Hematol. 2010;85:760-764.

37. Nabhan C, Byrtek M, Taylor MD, Friedberg JW, Cerhan JR, Hainsworth JD, Miller TP, Hirata J, Link BK, Flowers CR. Racial differences in presentation and management of follicular non-Hodgkin lymphoma in the United States: report from the National LymphoCare Study. Cancer. 2012;118:4842-4850.

38. Clarke CA, Glaser SL, Gomez SL, Wang SS, Keegan TH, Yang J, Chang ET. Lymphoid malignancies in U.S. Asians: incidence rate differences by birthplace and acculturation. Cancer Epidemiol Biomarkers Prev. 2011;20:1064-1077.

39. Vargo JA, Gill BS, Balasubramani GK, Beriwal S. What is the optimal management of early-stage low-grade follicular lymphoma in the modern era? Cancer. 2015;121:3325-3334.

40. Lowry L, Smith P, Qian W, Falk S, Benstead K, Illidge T, Linch D, Robinson M, Jack A, Hoskin P. Reduced dose radiotherapy for local control in non-Hodgkin lymphoma: a randomised phase III trial. Radiother Oncol. 2011;100:86-92. 
41. Lowry L, Ardeshna KM. Has single-agent rituximab replaced watch-and-wait for a patient with asymptomatic low-grade follicular lymphoma? Cancer J. 2012;18:390-395.

42. Ardeshna KM, Qian W, Smith P, Braganca N, Lowry L, Patrick P, Warden J, Stevens L, Pocock CF, Miall F, Cunningham D, Davies J, Jack A, et al. Rituximab versus a watch-and-wait approach in patients with advancedstage, asymptomatic, non-bulky follicular lymphoma: an open-label randomised phase 3 trial. Lancet Oncol. 2014; 15:424-435.

43. Peterson BA, Petroni GR, Frizzera G, Barcos M, Bloomfield CD, Nissen NI, Hurd DD, Henderson ES, Sartiano GP, Johnson JL, Holland JF, Gottlieb AJ. Prolonged single-agent versus combination chemotherapy in indolent follicular lymphomas: a study of the cancer and leukemia group B. J Clin Oncol. 2003;21:5-15.

44. Nabhan C, Aschebrook-Kilfoy B, Chiu BC, Kruczek K, Smith SM, Evens AM. The impact of race, age, and sex in follicular lymphoma: a comprehensive SEER analysis across consecutive treatment eras. Am J Hematol. 2014;89:633-638.

45. Clarke CA, Undurraga DM, Harasty PJ, Glaser SL, Morton LM, Holly EA. Changes in cancer registry coding for lymphoma subtypes: reliability over time and relevance for surveillance and study. Cancer Epidemiol Biomarkers Prev. 2006;15:630-638.
46. Surveillance, Epidemiology, and End Results (SEER) Program. Research Data 1973-2009 (November 2011 Submission). National Cancer Institute, DCCPS, Surveillance Research Program, Surveillance Sys-tems Branch. Released April 2012. http://www.seer.cancer.gov/.

47. National Cancer Institute. Number of Persons by Race and Hispanic Ethnicity for SEER Participants (2000 Census Data). http://seer.cancer.gov/registries/data.html. Accessed September 2013.

48. Bista A, Sharma S, Shah BK. Disparities in receipt of radiotherapy and survival by age, sex, and ethnicity among patient with stage I follicular lymphoma. Front Oncol. 2016;6:101.

49. Swerdlow SH, Campo E, Harris NL, Jaffe ES, Pileri SA, Stein H, Thiele J, Vardiman JW. WHO Classification of Tumors of Haematopoietic and Lymphoid Tissues. Lyon, France: IARC Press; 2008.

50. Jaffe ES. The 2008 WHO classification of lymphomas: implications for clinical practice and translational research. Hematology Am Soc Hematol Educ Program. 2009;2009:523-531. 